\title{
Bioactive dentin replacement
}

\author{
Dr Vipin Arora ${ }^{1}$, Dr Vineeta Nikhil ${ }^{2}$, Dr Namrata Sharma ${ }^{3}$, Dr Pooja Arora $^{4}$ \\ 1,2,3 (Department of Conservative Dentistry and Endodontics, Subharti Dental College, Meerut, India) \\ ${ }^{4}$ (Department of Prosthodontics and Dental Materials, Subharti Dental College, Meerut, India)
}

\begin{abstract}
Replacement of dentin with a material popularly marketed as Biodentine (Septodont, Saint Maur des Fausses, France), a new tricalcium silicate-based cement, has recently been commercialized and advertised as a bioactive material. Its clinical application and physical properties have been widely described. Biodentine, a new biologically active cement which has dentin-like mechanical properties and can be used as a dentin replacement in the tooth crown and root region. The cement consists mainly of a tri-and dicalcium silicate powder, which is mixed with an aqueous calcium chloride solution. As regards biocompatibility, longterm impermeability, antibacterial properties, induction of hard tissue regeneration, stability, low solubility, non-absorbability and ease of handling, Biodentine fulfils the requirements found in the literature for a material suitable for these purposes. On the basis of the good material properties of Biodentine, this cement is an interesting alternative to the conventional materials which were hitherto recommended. Biodentine can therefore confer advantages in day-to-day practice and with correct diagnosis contribute to the long-term maintenance of the vitality of the dental pulp and to the retention of teeth. However, little scientific data is available at present.
\end{abstract}

Keywords: biodentine, dentin, bioactive dentin replacement, tricalcium silicate-based cement, Portland cement

\section{Introduction}

A new bioactive cement, also called as smart dentin replacement and popularly known as Biodentine (Septodont, St. Maurdes-Fossés, France), was recently launched as a dentin substitute. It shares both its indications and mode of action with calcium hydroxide, but does not have its drawbacks.

Biodentine is a cement of the same class as MTA: this new calcium silicate-based material exhibits physical and chemical properties similar to those described for certain Portland cement derivatives. On the biological level, it is perfectly biocompatible [1] and capable of inducing the apposition of reactionary dentin by stimulating odontoblast activity[3] and reparative dentin, by induction of cell differentiation[2]. It is in effect a dentin substitute that can be used as a coronal restoration material (for indirect pulp capping), but can also be placed in contact with the pulp. Its faster setting time allows either immediate crown restoration[4], or to make it directly intraorally "functional" without fear of the material deteriorating.

Biodentine can be used both on the tooth crown and also in the region of the tooth root; in the crown region as a base, provisional seal, for deep caries therapy, as a cervical filling, for direct and indirect pulp capping and in pulpotomies. In the region of the tooth root, Biodentine can be used for the treatment of perforations of the root canal or pulp chamber floor, due to internal and external absorption processes, for apexification and as a retrograde root canal filling material. On the one hand, Biodentine serves as a dentin replacement (in the crown region as a base), and on the other hand for maintaining the vitality of the dental pulp or stimulation of hard tissue regeneration, i.e. both tertiary dentin formation and also bone regeneration, e.g. after root end surgery $[5,6]$.

Bioactive tricalcium silicate has several advantages over calcium hydroxide and mineral trioxide aggregates (MTA). The commercialized tricalcium silicate is different from the usual dental calcium silicate "Portland Cement" materials. The manufacturing process of the active biosilicate technology eliminates the metal impurities seen in the "Portland Cement" calcium silicates. The setting reaction is a hydration of tricalcium silicate which produces a calcium silicate gel and a calcium hydroxide. In contact with phosphate ions, it creates precipitates that resemble hydroxyapatite $[7,8]$. These precipitates from MTA and tricalcium silicate can be incorporated into root canal dentin. A comparison of the calcium and silica uptake of adjacent root canals treated with MTA versus tricalcium silicate demonstrated a greater uptake of the tricalcium silicate[9]. Using confocal microscopy there was an increase in the carbonate content of interfacial dentin, which suggested intertubular diffusion and mineral tags of Biodentine hydration products creating a hybrid zone [10]. Burgess and co-workers [11] characterized this hybrid zone as being microleakage free.

Histologically, the bioactive tricalcium silicate demonstrated the ability to induce odontoblast differentiation from pulp progenitor cells. The resulting mineralized matrix had the molecular characteristics of dentin. An evaluation comparing the biocompatibility of the tricalcium silicate with MTA and Dycal 
demonstrated that the Biodentine was equivalent to MTA (Dentsply) and more biocompatible than Dycal (Dentsply-Caulk). A clinical evaluation over 6-35 months of Biodentine as a base and for pulp capping demonstrated both biocompatibility and longevity $[1,7,8,12]$.

This review will cover all the aspects of this novel material to be used in dentistry.

\title{
II. Active Biosilicate Technology And Chemical Composition
}

This material was developed based on the most biocompatible chemistry available for dental materials: calcium silicates, which can set in the presence of water. Although recognized as highly biocompatible and bioactive, all these materials lack reactivity, with very long setting times (more than 2 hours), low mechanical properties and with very difficult handling (depending on the water ratio, from a sandy consistency to a fluid paste.This calcium silicate chemistry was combined with the requirements of a formulation compatible with classical restorative and endodontic practice, Septodont developed a new technological platform called Active Biosilicate Technology ${ }^{\mathrm{TM}}$. This consists in controlling every step of the material formulation beginning with the purity of the raw materials.

Usual dental calcium silicate cements are based on the "Portland Cement" materials, which result from the clinker products manufactured by the building industry from natural stone treatment. This implies that all these products inherently contain unpurifiable mixtures of calcium silicates $\left(\mathrm{C}_{3} \mathrm{~S}+\mathrm{C}_{2} \mathrm{~S}\right)$,calcium aluminates $\left(\mathrm{C}_{3} \mathrm{~A}\right)$,calcium alumino-ferrites $\left(\mathrm{C}_{4} \mathrm{AF}\right)$, calcium sulfates $\left(\mathrm{CaSO}_{4}\right.$-gypsum), together with low concentrations of metallic impurities coming from the natural minerals used as raw materials.[13,14]The Active Biosilicate Technology is a proprietary technology developed according to state-of-the-art pharmaceutical background applied to the high temperate ceramic mineral chemistry to ensure the purity of the calcium silicate content of the formulation and the absence of any aluminate and calcium sulphate in the final product. Inorder to reach a formulation with a short setting time (12minutes) and high mechanical properties in the range of natural dentine, calcium silicates could not be used alone.[13,14]

Usually calcium silicate cements have setting times in the range of several hours, which is too long in most of the protocols in clinical practice. Increasing the setting time was achieved by a combination of different effects. First, particle size greatly influences the setting time, since the higher the specific surface, the shorter the setting. Also, adding calcium chloride to the liquid component accelerates the system. Finally, the decrease of the liquid content in the system decreases the setting time to harden within 9 to12 minutes. Reaching high mechanical strength is also quite difficult for these systems. The first cause of low mechanical properties of Portland cements are the aluminate components, which make the product fragile. The manufacturer controls the purity of the calcium silicate through the Active Biosilicate Technology ${ }^{\mathrm{TM}}$ which consists in eliminating aluminates and other impurities [13].

The second axis of formulation was to adjust the particle size distribution in order to reach an optimal Powder density.The additional charge system selected was calcium carbonate, for both its biocompatibility and calcium content.The paradox of calcium silicate systems is also that water, which is essential for the hardening of the product, canal so affect the strength of the material. On the hand, excess water in the system will create some remaining porosity, significantly degrading the macroscopic mechanical resistance, but on the other hand decreasing the water content leads to reducing the possibility of a homogenous mix. The addition of hydro soluble polymer systems described as "water reducing agents" or super plasticizers, helps in maintaining the balance between low water content and consistency of the mixture. Radiopacity is obtained by adding zirconium oxide to the final product $[13,14]$.

Biodentine consists of a powder in a capsule and liquid in a pipette. The powder mainly contains tricalcium and dicalcium silicate, the principal component of Portland cement, as well as calcium carbonate. Zirconium dioxide serves as contrast medium. The liquid consists of calcium chloride in aqueous solution with an admixture of polycarboxylate. The powder is mixed with the liquid in a capsule in the triturator for 30 seconds. Once mixed, Biodentine sets in about 12 minutes. During the setting of the cement calcium hydroxide is formed.[13,14]

\section{Powder}

Tri-calcium Silicate (C3S)

Di-calcium Silicate (C2S)

Calcium Carbonate and Oxide

Iron Oxide

Zirconium Oxide

\author{
Main core material \\ Second core material \\ Filler \\ Shade \\ Radiopacifier
}




\section{Liquid}

Calcium chloride

Hydrosoluble polymer
Accelerator

Water reducing agent

\section{Setting reaction (2)}

The calcium silicate has the ability to interact with water leading to the setting and hardening of the cement. This is a hydration of the tricalcium silicate $(3 \mathrm{CaO} . \mathrm{SiO} 2=\mathrm{C} 3 \mathrm{~S})$ which produces a hydrated calcium silicate gel $(\mathrm{CSH}$ gel) and calcium hydroxide $(\mathrm{Ca}(\mathrm{OH}) 2)$.

$$
\begin{gathered}
2\left(3 \mathrm{CaO} . \mathrm{SiO}_{2}\right)+6 \mathrm{H}_{2} \mathrm{O}=3 \mathrm{CaO} \cdot 2 \mathrm{SiO}_{2} \cdot 3 \mathrm{H}_{2} \mathrm{O}+3 \mathrm{Ca}(\mathrm{OH})_{2} \\
\mathrm{C}_{3} \mathrm{SCSH}
\end{gathered}
$$

This dissolution process occurs at the surface of each grain of calcium silicate. The hydrated calcium silicate gel and the excess of calcium hydroxide tend to precipitate at the surface of the particles and in the pores of the powder, due to saturation of the medium. This precipitation process is reinforced in systems with low water content.

The unreacted tricalcium silicate grains are surrounded by layers of calcium silicate hydrated gel, which are relatively impermeable to water, thereby slowing down the effects of further reactions. The C-S-H gel formation is due to the permanent hydration of the tricalcium silicate, which gradually fills in the spaces between the tricalcium silicate grains. The hardening process results from of the formation of crystals that are deposited in a supersaturated solution. The working time of Biodentineis up to 6 minutes with a final set at around 10-12 minutes.

Biodentine has a consistency after mixing which enables manipulation with a spatula, with an amalgam carrier or with carriers which are used for endodontic cements in retrograde fillings (Messing gun, MTA gun).

1. Density: $2.260(0.002) \mathrm{g} / \mathrm{cm}^{3}$

\section{Physical And Mechanical Properties}

2. Porosity: $6.8(0.2) \%$.

\section{Compressive strength:}

There is a sharp increase in the compressive strength reaching more than $100 \mathrm{MPa}$ in the first hour. The mechanical strength continues to improve to reach more than $200 \mathrm{MPa}$ at $24 \mathrm{~h}$ which is more than most glass ionomers values. A specific feature of Biodentine is its capacity to continue improving with time over several days until reaching $300 \mathrm{MPa}$ after one month. This value becomes quite stable and is in the range of the compressive strength of natural dentin $(297 \mathrm{MPa})$. This maturation process can be related to the decrease of porosity with time, which was illustrated previously. Biodentine is an evolutive biomaterial which improves its mechanical properties with time.This demonstrates the superiority of Biodentine for building in short time (9-12min) sufficient mechanical resistance to be used as a dentine substitute, compatible with dental restorations.[3,6,13,14]

\section{Flexural strength: $22 \mathrm{MPa}$}

5. Vickers micro hardness: The hardness increases in time when cements are immersed in distilled water. After 2 hours, the hardness of Biodentine was $51 \mathrm{HVN}$ and reached $69 \mathrm{HVN}$ after 1 month. The reported micro hardness values for natural dentin are in the range of 60-90 HVN (O'Brien 2008). Biodentine has surface hardness in the same range as natural dentin [3,6,13-15].

6. Radiopacity: displays a radiopacity equivalent to $3.5 \mathrm{~mm}$ of aluminium $[13,14]$.

7. Stablity in oral Enviroment: The material properties of Biodentine are similar to those of dentin. Both the elasticity modulus of the cement and also the pressure resistance, bending strength and Vickers hardness are comparable with dentin and, except for the Vickers hardness, lie above the values that can be measured on glass ionomer cements. However, Biodentine is not as stable as a composite material, so that Biodentine is not suitable for a permanent enamel replacement. However, in comparison to other Portland cement- based products, Bio dentin ${ }^{\mathrm{TM}}$ is stable enough to find use as a temporary filling even in the chewing load bearing region $[3,6,13-15]$. 
8. Induces the formation of hard tissue: Tricalcium silicate is a main component of Biodentine, MTA and Portland cement. In addition to their biocompatibility, materials of this type are known to be biologically active (Laurent et al. 2009). Biological activity refers to a positive effect of a medicine or material on living tissue. A material is described as biologically active if it interacts with cells of the human body or has an advantageous action on cells [3,6,13-15]. In studies of bio-mineralisation, bioactivity mostly refers to the promotion of hard tissue formation which is induced by a material. As regards the biological activity of Biodentine, it could be shown in vitro that dental pulp fibroblasts form so-called mineralisation nuclei after the cement has been added to the cell medium. These mineralisation nuclei have the molecular characteristics of dentin.

This indicates a promotion of the transformation of the dental pulp fibroblasts by Biodentine to odontoblastlike cells which can then form hard tissue.

9. Bacteriostatic: During the setting phase of Biodentine, calcium hydroxide ions are released from the cement. This results in a $\mathrm{pH}$ of about 12.5 and a basification of the surroundings. This high $\mathrm{pH}$ inhibit the growth of microorganisms and can disinfect the dentin [16].

\section{Indications}

Biodentine, the first biocompatible and bioactive material can be used wherever dentine is damaged. Biodentine uniqueness not only lies in its innovative bioactive and "pulp-protective" chemistry, but also in its universal application, both in the crown and in the root.

Dentine substitute under a composite [3,6,13-15]

- temporary enamel restoration,

- permanent dentin restoration,

- deep or large carious lesions,

- deep cervical or radicular lesions,

- pulpotomy

\section{Endodontic repair material [3,6,13-15]}

The endodontic indications of Biodentine are similar to the usual calcium silicate based materials, like the Portland cements (i.e.ProRoot MTA).This type of product is already well documented. Several physical, chemical and biological properties are comparable. However, Biodentine has some features which are superior to MTA.

Biodentine consistency is better suited to the clinical use than MTA's.

Biodentine presentation ensures a better handling and safety than MTA.

Biodentine does not require a two step obturation as in the case of MTA. As the setting is faster, there is a lower risk of bacterial contamination than with MTA.[3,6,13-15]

- $\quad$ Direct pulp capping following carious pulp exposure

- Direct pulp capping following dental trauma/injury to healthy pulp(partial pulpotomy)

- Repair of perforated root canals and/or pulp chamber floor

- Retrograde endodontic surgery

- Pulpotomy in primary molars

- Apexification

\section{Benefits Of Biodentine [1,12-15]}

- Versatile: Usable for pulp caps to bulk fill, does not stain, has excellent radiopacity, and there is no surface preparation or tedious bonding required due to the micro-mechanical anchorage.

- Saves teeth: Has higher compressive strength than dentin, preserves pulp, and promotes pulp healing eliminating RCT (root canal therapy) in most cases.

- Excellent sealing properties: Outstanding microleakage resistance, enhanced by the absence of shrinkage due to the resin-free formula.

- Sets in ten minutes: Allows full restorations to be completed in one office visit! Proven clinical results.

- No surface preparation: micro-mechanical anchorage, no tedious bonding is required.

- Excellent sealing properties: mineral tags in the dentin tubules. 
- Outstanding microleakage resistance, enhanced by the absence of shrinkage thanks to the resin-free formula.

- High dimensional stability:long lasting sealing properties.

- Biodentine prevents caries recurrence in deep cavities thanks to its alkaline $\mathrm{pH}(\mathrm{pH}=12)$ giving it bacteriostatic properties.

- Excellent radiopacity

\section{Critical Analysis}

The studies mentioning the role of this new material are discussed and critically analysed.

\begin{tabular}{|c|c|}
\hline Authors (year) & Analysis of the Inference \\
\hline $\begin{array}{l}\text { Shamkhalov GSet al,2013 } \\
\text { [17] } \\
\text { In vitro }\end{array}$ & $\begin{array}{l}\text { Examined materials ("Biodentine" (Septodont), "Rootdent" (TehnoDent) and adhesive "Futurabond } \\
\text { HP" (Voco)) for antibacterial activity against E. coli, S. aureus, C. albicans, Str. faecalis. The results } \\
\text { confirmed the analyzed materials to be a useful tool for deep caries lesions treatment. }\end{array}$ \\
\hline Camilleri J.,2013 [18] & $\begin{array}{l}\text { Biodentine demonstrated both structural and chemical changes when etched with } 37 \% \text { phosphoric } \\
\text { acid. Biodentine exhibited a lower calcium to silicon ratio and a reduction in the chloride peak height } \\
\text { when etched. When used as a dentine replacement material in the sandwich technique overlayed with } \\
\text { composite, significant leakage occurred at the dentine to material interface. On the other hand } \\
\text { materials based on glass ionomer cement were etched successfully and no chemical and physical } \\
\text { changes or micro-leakage were detected when the materials were used as bases under composite } \\
\text { restorations. The micro-hardness of all the materials was unaffected by etching. }\end{array}$ \\
\hline $\begin{array}{l}\text { Nowicka A et al,2013 } \\
{[19]}\end{array}$ & $\begin{array}{l}\text { The majority of specimens showed complete dentinal bridge formation and an absence of } \\
\text { inflammatory pulp response. Layers of well-arranged odontoblast and odontoblast-like cells were } \\
\text { found to form tubular dentin under the osteodentin. Within the limitations of this study, Biodentine } \\
\text { had a similar efficacy in the clinical setting and was considered an interesting alternative to MTA in } \\
\text { pulp-capping treatment during vital pulp therapy. }\end{array}$ \\
\hline $\begin{array}{l}\text { Vallés Met al,2013 [20] } \\
\text { In vitro }\end{array}$ & $\begin{array}{l}\text { The combination of light and anaerobic conditions (similar to those in clinical situations) results in } \\
\text { differences in color of the tested calcium silicate-based material( CSMs) during a period of } 5 \text { days, of } \\
\text { which Biodentine and White Portland Cement (PC) demonstrated color stability. }\end{array}$ \\
\hline $\begin{array}{l}\text { Zhou HMet al,2013 [21] } \\
\text { In vitro }\end{array}$ & $\begin{array}{l}\text { Cells exposed to extracts from Biodentine and MTA showed the highest viabilities of human gingival } \\
\text { fibroblasts. at all extract concentrations, whereas cells exposed to glass ionomer cement extracts } \\
\text { displayed the lowest viabilities. Biodentine caused gingival fibroblast reaction similar to that by MTA. } \\
\text { Both materials were less cytotoxic than glass ionomer cement. }\end{array}$ \\
\hline $\begin{array}{l}\text { Han Let al,2013 [22] } \\
\text { In vitro }\end{array}$ & $\begin{array}{l}\text { Compared white ProRoot MTA (WMTA), EndoSequence BC sealer (BC sealer) and Biodentine with } \\
\text { regard to their ability to produce apatites and cause } \mathrm{Ca} \text { and } \mathrm{Si} \text { incorporation in adjacent human root } \\
\text { canal dentine after immersion in phosphate-buffered saline (PBS). Compared with Biodentine and } \\
\text { WMTA, BC sealer showed less Ca ion release and did not show Ca and Si incorporation as deeply in } \\
\text { human root canal dentine when immersed in PBS for up to } 90 \text { days. }\end{array}$ \\
\hline $\begin{array}{l}\text { Grech Let al, } 2013 \text { [23] } \\
\text { In vitro }\end{array}$ & $\begin{array}{l}\text { The hydrated materials were composed of a cementitous phase that was rich in calcium and silicon } \\
\text { and a radiopacifying material. Biodentine included calcium carbonate, and Bioaggregate included } \\
\text { silica and calcium phosphate in the powders. IRM was composed of zinc oxide interspersed in a } \\
\text { matrix of organic material. }\end{array}$ \\
\hline $\begin{array}{l}\text { Shayegan A et al,2012 } \\
{[24]} \\
\text { In vivo }\end{array}$ & $\begin{array}{l}\text { Assesed and compared, in primary pig teeth, the pulp response after a pulpotomy using either } \\
\text { Biodentine (a new tricalcium-silicate cement), white mineral trioxide aggregate (WMTA), or } \\
\text { formocresol (FC) and repeat the same after direct pulp capping using either Biodentine, WMTA, or } \\
\text { calcium hydroxide. They concluded that Biodentine and white mineral trioxide aggregate are both } \\
\text { suitable, biocompatible materials for pulp capping in primary teeth of pigs. }\end{array}$ \\
\hline $\begin{array}{l}\text { Grech Let al, } 2013 \text { [25] } \\
\text { In vitro }\end{array}$ & $\begin{array}{l}\text { The physical properties of prototype radiopacified tricalcium silicate cement, Bio aggregate and } \\
\text { Biodentine were investigated. Intermediate restorative material was used as a control. All the } \\
\text { materials tested had a radiopacity value higher than } 3 \mathrm{~mm} \text { thickness of aluminum. IRM exhibited the } \\
\text { highest radiopacity. Biodentine demonstrated a high washout, low fluid uptake and sorption values, } \\
\text { low setting time and superior mechanical properties. The fluid uptake and setting time was the highest } \\
\text { for Bioaggregate. }\end{array}$ \\
\hline $\begin{array}{l}\text { Tran XV et al,2012 [26] } \\
\text { In vitro }\end{array}$ & $\begin{array}{l}\text { Evaluated the capacity of a new calcium-silicate-based restorative cement (biodentine) as compared } \\
\text { to calcium hydroxide and MTA to induce pulp healing in a rat pulp injury model. At day } 7 \text {, results } \\
\text { showed that both the evaluated cement and MTA induced cell proliferation and formation of } \\
\text { mineralization foci, which were strongly positive for osteopontin. At longer time-points, we observed } \\
\text { the formation of a homogeneous dentin bridge at the injury site, secreted by cells displaying an } \\
\text { odontoblastic phenotype. In contrast, the reparative tissue induced by } \mathrm{Ca}(\mathrm{OH})_{2} \text { showed porous } \\
\text { organization, suggesting a reparative process different from those induced by calcium silicate }\end{array}$ \\
\hline
\end{tabular}




\begin{tabular}{|c|c|}
\hline & ments. \\
\hline $\begin{array}{l}\text { Zanini Met al, } 2012 \text { [27] } \\
\text { In vitro }\end{array}$ & $\begin{array}{l}\text { Evaluated the biological effect of Biodentine on immortalized murine pulp cells (OD-21). The } \\
\text { expression patterns of several genes confirmed the differentiation of OD- } 21 \text { cells into odontoblasts } \\
\text { during the period of cell culture. Results suggested that Biodentine is bioactive because it increased } \\
\text { OD- } 21 \text { cell proliferation and biomineralization. }\end{array}$ \\
\hline Raskin Aet al ,2012 [28] & $\begin{array}{l}\text { Within the limits of this in vitro study, Biodentine as dentin substitute in cervical lining restorations or } \\
\text { as a restorative material in approximal cavities when the cervical extent is under the CEJ seems to } \\
\text { perform well without any conditioning treatment. However, the operating time is longer than when a } \\
\text { RMGIC (Fuji II LC) is used. }\end{array}$ \\
\hline $\begin{array}{l}\text { Leiendecker APet al [29] } \\
2012\end{array}$ & $\begin{array}{l}\text { Studie the effects of calcium silicate-based materials on collagen matrix integrity of mineralized } \\
\text { dentin. They concluded that Prolonged contact of mineralized dentin with CSMs has an adverse effect } \\
\text { on the integrity of the dentin collagen matrix. However, the amount of collagen extracted was limited } \\
\text { to the contact surface. Clinicians can continue to apply CSMs in endodontic procedures; however, } \\
\text { caution is advised when these materials are applied to thin dentinal walls. }\end{array}$ \\
\hline Koubi G et al,2013 [30] & $\begin{array}{l}\text { A multicentric randomized, 3-year prospective study was conducted to determine for how long } \\
\text { Biodentine, a new biocompatible dentine substitute, can remain as a posterior restoration.It was } \\
\text { concluded that resistance to marginal discoloration was superior with Biodentine compared to Z100@. } \\
\text { When Biodentine was retained as a dentine substitute after pulp vitality control, it was covered } \\
\text { systematically with the composite Z100@. This procedure yielded restorations that were clinically } \\
\text { sound and symptom free. }\end{array}$ \\
\hline $\begin{array}{l}\text { Laurent Pet al,2012 [31] } \\
\text { In vitro }\end{array}$ & $\begin{array}{l}\text { assessed the ability of a recently developed tricalcium silicate-based cement (Biodentine }{ }^{\mathrm{TM}} \text { ) to induce } \\
\text { reparative dentine synthesis and to investigate its capacity to modulate pulp cells TGF- } \beta 1 \text { secretion. } \\
\text { Biodentine }{ }^{\mathrm{TM}} \text { induced mineralized foci formation early after its application. The mineralization } \\
\text { appeared under the form of osteodentine and expressed markers of odontoblasts. Biodentine } \\
\text { significantly increased TGF- } \beta 1 \text { secretion from pulp cells independently of the contact surface } \\
\text { increase. }\end{array}$ \\
\hline $\begin{array}{l}\text { Morejón-Alonso L et al } \\
2012 \text { [32] }\end{array}$ & $\begin{array}{l}\text { Silicon compounds are known as bioactive materials that are able to bond to the living bone tissue by } \\
\text { inducing an osteogenic response through the stimulation and activation of osteoblasts. To improve the } \\
\text { bioactive and mechanical properties of an } \alpha-\mathrm{Ca}(3) \mathrm{PO}(4) \text {-based cement, the effects of the addition of } \\
\mathrm{Ca}(3 \mathrm{SiO}(5)(\mathrm{C}(3) \mathrm{S}) \text { on physical, chemical, mechanical, and biological properties after soaking in } \\
\text { simulated body fluid (SBF) were studied. The morphological and structural changes of the material } \\
\text { during immersion were analyzed by X-ray diffraction and scanning electron microscopy. The results } \\
\text { showed that it is possible to increase the compressive strength of the cement by adding } 5 \% \text { of } \mathrm{C}_{3} \mathrm{~S} \text {. } \\
\text { Higher } \mathrm{C}(3) \mathrm{S} \text { contents enhance bioactivity and biocompatibility by the formation of a dense and } \\
\text { homogeneous hydroxyapatite layer within } 7 \text { days; however, compressive strength decreases } \\
\text { drastically as a consequence of delayed hydrolysis of } \alpha-\mathrm{Ca}_{3}(\mathrm{PO} 4)_{2} \text {. }\end{array}$ \\
\hline
\end{tabular}

\section{Conclusion}

Overall, Biodentine is an interesting, very promising product, which with correct diagnosis can certainly contribute to a high degree to maintenance of the vitality of the dental pulp or to the retention of a tooth. Unfortunately at present little scientific published data on Biodentine is available. More scientific studies on Biodentine are therefore absolutely necessary.

\section{References}

[1]. Wang X, Sun H, Chang J (2008). Characterization of Ca3SiO5/CaCl2 composite cement for dental application. Dent Mater. 24:74-82.

[2]. Shayegan A. et al.: Biodentine: A new material used as pulp-capping agent in primary pig teeth. Poster at IADT 16th World Congress Dental Traumatology. Verona 2010

[3]. Tran V. et al.: Microleakage of a new restorative calcium based cement (Biodentine®). Oral presentationPEF IADR, London 2008.

[4]. Biodentine- Product information. Septodont GmbH, 2010.(https://www.google.co.in/\#q=biodentine\%2Cproduct+information)

[5]. Koubi GF, Franquin JC, Colon P. A clinical study of a new Ca3SiO5-based material indicated as a dentin substitute. Conseuro 2009, Seville, Spain. March, 2009.

[6]. Colon P, Bronnec F, Grosgogeat B, Pradelle-Plasse N. Interactions between a calcium silicate cement (Biodentine) and its environment. J Dent Res. 2010;89:Abstract no. 401.

[7]. Atmeh A. Dynamic bioactive interface with dental tissues. 45th Meeting of the Continental European Division of the IADR (CED-IADR) with the Scandanavian Division (NOF). 2011; Abstract no. 1.

[8]. Laurent P, Camps J., Déjou J, About I. Induction of specific cell responses to a Ca3SiO5-based posterior restorative material. Dent Mater. 2008; 24:1486-94

[9]. Atmeh AR, Chong EZ, Richard G, Festy F, Watson TF. Dentin-cement interfacial interaction: calcium silicates and polyalkenoates. J Dent Res. 2012, May;91(5):454-9.

[10]. Bentley K, Janyavula S, Cakir D, Beck P, Ramp L, Burgess J. Mechanical and physical properties of vital pulp therapy materials J Dent Res (AADR Abstracts). 2012; 91: abstract no. 258.

[11]. Shamkhalov GS, Ivanova EV, Dmitrieva NA, Akhmedova ZR. Comparative study of antimicrobial activity of "Biodentine" and "Rootdent" cements and "Futurabond HP" adhesive. Stomatologiia (Mosk). 2013;92(4):37-39. Russian.

[12]. Goldberg M, Pradelle-Plasse N, Tran X, et al. Emerging trends in (bio)compatible researches. In:Goldberg M. ed. Biocompatibility or cytotoxic effects of dental composites. Oxford. UK:Coxmoor Publishing. 2009; pp. 181-203.

[13]. Biodentine:activebiosilicate technology, scientific file, Septodont(www.septodont.fr/fichiers_upload/biodentinescientificfile.pdf)

[14]. Focus on biodentine:case studies,SSeptodent.(http://www.septodont.com.hr/pdf/biodentine_cs_1.pdf) 
[15]. About I, O’Brien W 2008 Dental Materials and their Selection. O’Brien W 4th ed. Ed

[16]. Firla M.: Dentin-Ersatzmaterial auf der Basis der Active Biosilicate Technology. DZW Kompakt 2011;14: (1) 11-14.

[17]. Shamkhalov GS, Ivanova EV, Dmitrieva NA, Akhmedova ZR. Comparative study of antimicrobial activity of "Biodentine" and "Rootdent" cements and "Futurabond HP" adhesive. Stomatologiia (Mosk). 2013;92(4):37-39. Russian.

[18]. CamilleriJ .Investigation of Biodentinee as dentine replacement material..J Dent. 2013 Jul;41(7):600-10.

[19]. .Nowicka A, Lipski M, Parafiniuk M, Sporniak-Tutak K, Lichota D, Kosierkiewicz A, Kaczmarek W, Buczkowska-Radlińska J Response of human dental pulp capped with biodentinee and mineral trioxide aggregate .J Endod. 2013 Jun;39(6):743-7.

[20]. Vallés M, Mercadé M, Duran-Sindreu F, Bourdelande JL, Roig M. Influence of light and oxygen on the color stability of five calcium silicate-based materials.JEndod. 2013 Apr;39(4):525-8

[21]. ZZhou HM, Shen Y, Wang ZJ, Li L, Zheng YF, Häkkinen L, Haapasalo M. In Vitro cytotoxicity evaluation of a novel root repair material J Endod. 2013 Apr;39(4):478-83.

[22]. Han L, Okiji T. Bioactivity evaluation of three calcium silicate-based endodontic materialsIntEndod J. 2013 Sep;46(9):808-14

[23]. Grech L, Mallia B, Camilleri J. Characterization of set Intermediate Restorative Material, Biodentinee, Bioaggregate and a prototype calcium silicate cement for use as root-end filling materials.IntEndod J. 2013 Jul;46(7):632-41.

[24]. Shayegan A, Jurysta C, Atash R, Petein M, Abbeele AV. Biodentine used as a pulp-capping agent in primary pig teeth..Pediatr Dent. 2012 Nov-Dec;34(7):e202-8

[25]. Grech L, Mallia B, Camilleri.Investigation of the physical properties of tricalcium silicate cement-based root-end filling materials.J.Dent Mater. 2013 Feb;29(2):e20-8.

[26]. Tran XV, Gorin C, Willig C, Baroukh B, Pellat B, Decup F, Opsahl Vital S, Chaussain C, BoukpessiT.Effect of a calciumsilicate-based restorative cement on pulp repair..J Dent Res. 2012 Dec;91(12):1166-71.

[27]. Zanini M, Sautier JM, Berdal A, Simon S. Biodentinee induces immortalized murine pulp cell differentiation into odontoblastlike cells and stimulates biomineralization.JEndod. 2012 Sep;38(9):1220-6.

[28]. Raskin A, Eschrich G, Dejou J, About I. In vitro microleakage of Biodentinee as a dentin substitute compared to Fuji II LC in cervical lining restorations.JAdhes Dent. 2012 Dec;14(6):535-42.

[29]. Leiendecker AP, Qi YP, Sawyer AN, Niu LN, Agee KA, Loushine RJ, Weller RN, Pashley DH, Tay FR. Effects of calcium silicate-based materials on collagen matrix integrity of mineralized dentin J Endod. 2012 Jun;38(6):829-33

[30]. Koubi G, Colon P, Franquin JC, Hartmann A, Richard G, Faure MO, Lambert G. Clinical evaluation of the performance and safety of a new dentine substitute, Biodentinee, in the restoration of posterior teeth - a prospective study. Clin Oral Investig. 2013 Jan; 17(1):243-9.

[31]. Laurent P, Camps J, About I. Biodentine(TM) induces TGF- $\beta 1$ release from human pulp cells and early dental pulp mineralization. IntEndod J. 2012 May;45(5):439-48.

[32]. Morejón-Alonso L, Ferreira OJ, Carrodeguas RG, dos Santos LA. Bioactive composite bone cement based on $\alpha$-tricalcium phosphate/tricalciumsilicate.J Biomed Mater Res B ApplBiomater. 2012 Jan; 100(1):94-102. 